\title{
Double-Catheter Technique for the Proper Insertion of Umbilical Venous Catheters in Newborns
}

\author{
Mazen Al-Essa ${ }^{a}$ Nabil Rashwan ${ }^{b} \quad$ L.V. Devarajan ${ }^{a}$ \\ ${ }^{a}$ Department of Pediatrics, Faculty of Medicine, Kuwait University, Safat, and ${ }^{\mathrm{b}}$ Department of Neonatology, \\ Maternity Hospital, Sulaibikhat, Kuwait
}

\section{Key Words}

Umbilical vein · Double catheter · Newborn

\begin{abstract}
Objectives: To document the usefulness and safety of inserting a second umbilical venous catheter in ill neonates, while a previously misplaced first catheter was still in its place. Subjects and Methods: The case series involved 25 newborn babies who were admitted to the Neonatal Intensive Care Unit, Maternity Hospital, Kuwait, over a 3-year period from 1999 to 2002. The umbilical venous catheter of the babies was misplaced and diverted to the liver, necessitating insertion of a second catheter while the previous one was still in place. The characteristics of the babies and possible catheter-related complications were recorded. Results: Of the 25 babies, 19 had the second catheter properly placed in the right atrium, while in the remaining 6 neonates, the catheter was still misplaced. Misplacement occurred mostly in full-term babies or the catheter was inserted at a later stage. No life-threatening complication was observed during the procedure. Conclusion: Insertion of a second umbilical venous catheter with the misplaced first catheter in situ is a useful and safe procedure.
\end{abstract}

Copyright $(2005$ S. Karger AG, Basel

\section{KARGER}

Fax +4161306 1234 E-Mailkarger@karger.ch www.karger.com

\section{Introduction}

Central venous access is one of the necessary procedures in the care of newborn infants in the intensive care unit. Umbilical venous catheterization is used for central venous access in many neonatal intensive care units for various reasons. It is a simple procedure, has fewer complications than a central line inserted peripherally and does not require skin incision or a venous cut-down [1-3]. The ideal position of the umbilical venous catheter is in the right atrium, that can be confirmed on a plain X-ray of the abdomen with the tip of the catheter lying just above the diaphragm. However, it is not always done correctly, in some cases because the catheter gets diverted towards the portal veins away from the inferior vena cava. When this happens, complications may arise due to thrombosis and infection of the vein or the metabolic effects of the drugs given through this route on the liver $[4,5]$. Pericardial effusion has also been reported as one of the complications $[6,7]$.

There have been 2 case reports and a case series with a limited number of patients have been reported in which a second umbilical venous catheter was successfully inserted while the misplaced first catheter was still in situ $[8,9]$, hence we decided to conduct a study involving a larger series of patients to confirm the usefulness of the procedure. 


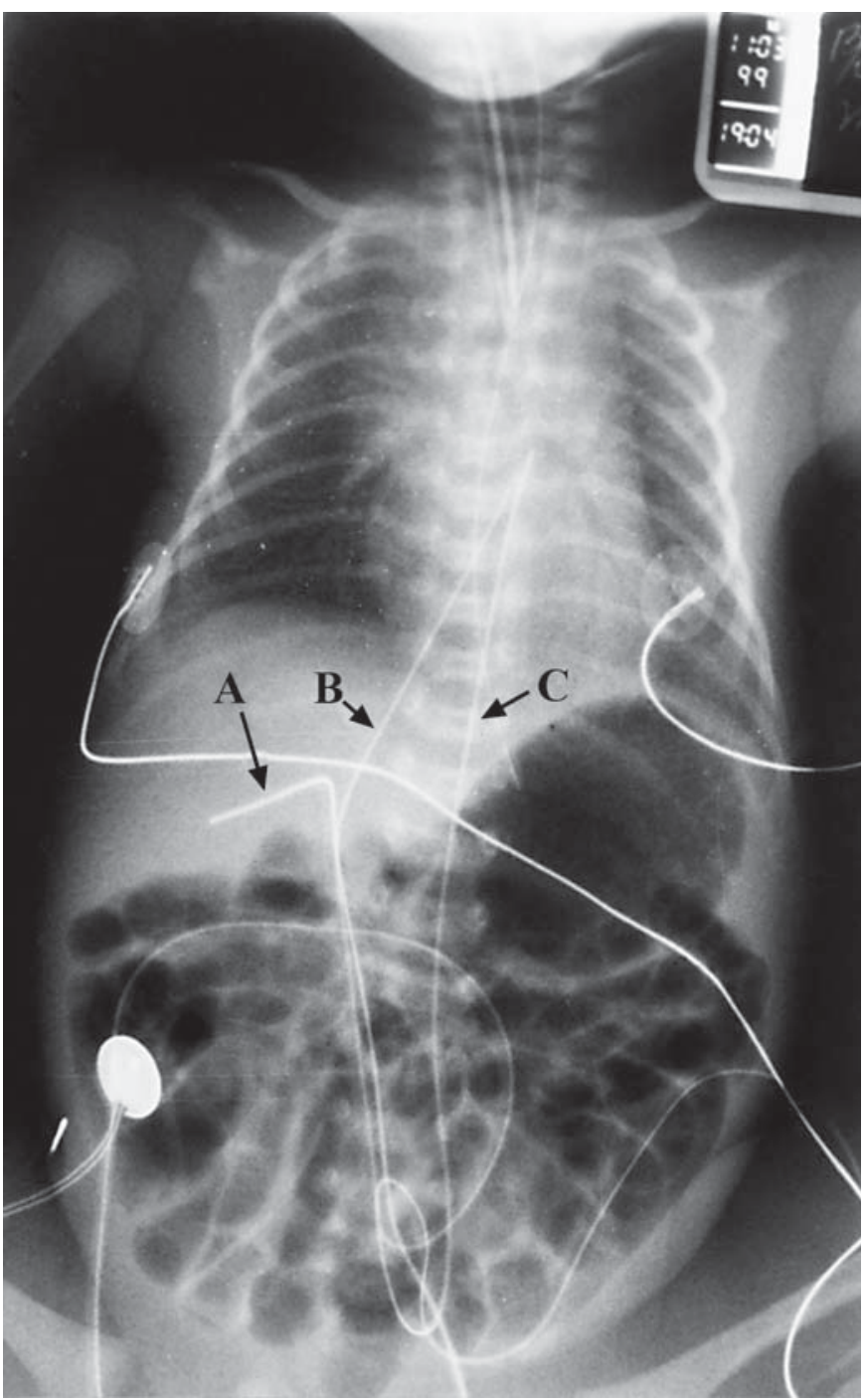

Fig. 1. Umbilical venous catheters. $A=$ First catheter; $B=$ second catheter; $\mathrm{C}=$ umbilical artery.

\section{Subjects and Methods}

Of approximately 300 newborn admissions per year to the Neonatal Intensive Care Unit, Maternity Hospital, Kuwait, 225 required umbilical venous catheterization mostly for blood sampling and then as a central venous access. We followed consecutively those infants who required catheterization immediately after the procedure with X-rays of the chest and abdomen. 17 infants had respiratory distress syndrome, three had persistent pulmonary hypertension of the newborn, one had pneumonia, one had pulmonary hypoplasia, one hypoxic-ischemic encephalopathy, one congenital heart disease and one epidermolysis bullosa. The proper insertion of the catheter was achieved by using the formula developed by Shukla and Ferrara [10], aiming the tip of the catheter in the right atrium, i.e. just above the diaphragm as seen on the $\mathrm{X}$ rays. The size of the catheters used were either F 3.5 or F 5 depend-
Table 1. Characteristics and data on the procedure in the study patients

\begin{tabular}{|c|c|c|c|c|c|}
\hline No. & Sex & $\begin{array}{l}\text { Birth } \\
\text { weight } \\
\mathrm{g}\end{array}$ & $\begin{array}{l}\text { Gesta- } \\
\text { tional age } \\
\text { weeks }\end{array}$ & $\begin{array}{l}\text { Age }(\mathrm{h}) \text { of } \\
\text { catheterization }\end{array}$ & Result \\
\hline 1 & male & 500 & 25 & $<12$ & success \\
\hline 2 & female & 730 & 25 & $<12$ & success \\
\hline 3 & male & 750 & 29 & $<12$ & success \\
\hline 4 & male & 800 & 27 & $<12$ & success \\
\hline 5 & female & 810 & 26 & $<12$ & success \\
\hline 6 & male & 930 & 27 & $<12$ & success \\
\hline 7 & female & 1,011 & 28 & $<12$ & success \\
\hline 8 & female & 1,050 & 29 & $<24$ & success \\
\hline 9 & male & 1,150 & 31 & $<12$ & failure \\
\hline 10 & female & 1,300 & 32 & $<12$ & success \\
\hline 11 & female & 1,320 & 34 & $<12$ & success \\
\hline 12 & female & 1,484 & 36 & $<12$ & success \\
\hline 13 & female & 1,495 & 32 & $<24$ & success \\
\hline 14 & male & 1,850 & 35 & $<12$ & success \\
\hline 15 & male & 1,900 & 36 & $<12$ & success \\
\hline 16 & male & 1,910 & 36 & $<24$ & success \\
\hline 17 & male & 2,000 & 35 & $<24$ & success \\
\hline 18 & male & 2,240 & 35 & $<12$ & success \\
\hline 19 & male & 2,400 & 44 & $<24$ & failure \\
\hline 20 & female & 2,450 & 38 & $<12$ & failure \\
\hline 21 & male & 3,105 & 40 & $>72$ & failure \\
\hline 22 & male & 3,500 & 40 & $>96$ & failure \\
\hline 23 & male & 3,800 & 40 & $<24$ & failure \\
\hline 24 & male & 3,950 & 38 & $<24$ & success \\
\hline 25 & female & 3,950 & 40 & $<24$ & success \\
\hline
\end{tabular}

ing on the size of the baby. In those babies where the catheter was diverted towards the portal vein, a second catheter of the same size was introduced within $1 \mathrm{~h}$ while the misplaced one was still in its original position. A second set of X-rays was taken to confirm the position of the second catheter. If the second catheter was in the right atrium, the first catheter was pulled out and the procedure was declared as a success, otherwise a failure.

During a 3-year period (1999-2002), 25 newborn babies were involved in this study. The following data were collected: sex, gestational age, birth weight, diagnosis, indications for catheterization, the insertion length of both catheters and the ease of insertion as recorded by the neonatal staff. Blockage of the catheter lumen was documented by Doppler ultrasonography. All catheter tips were sent for culture at the time of removal to document any sepsis.

\section{Results}

The characteristics of the infants are shown in table 1. Nineteen babies (76\%) had a second catheter successfully inserted in the right atrium within the first day of life. There were 6 failures, 5 full-term babies and 1 preterm, 2 of whom had catheterization on the fourth and fifth days (patients 21 and 22) of life and the remaining 4 were 


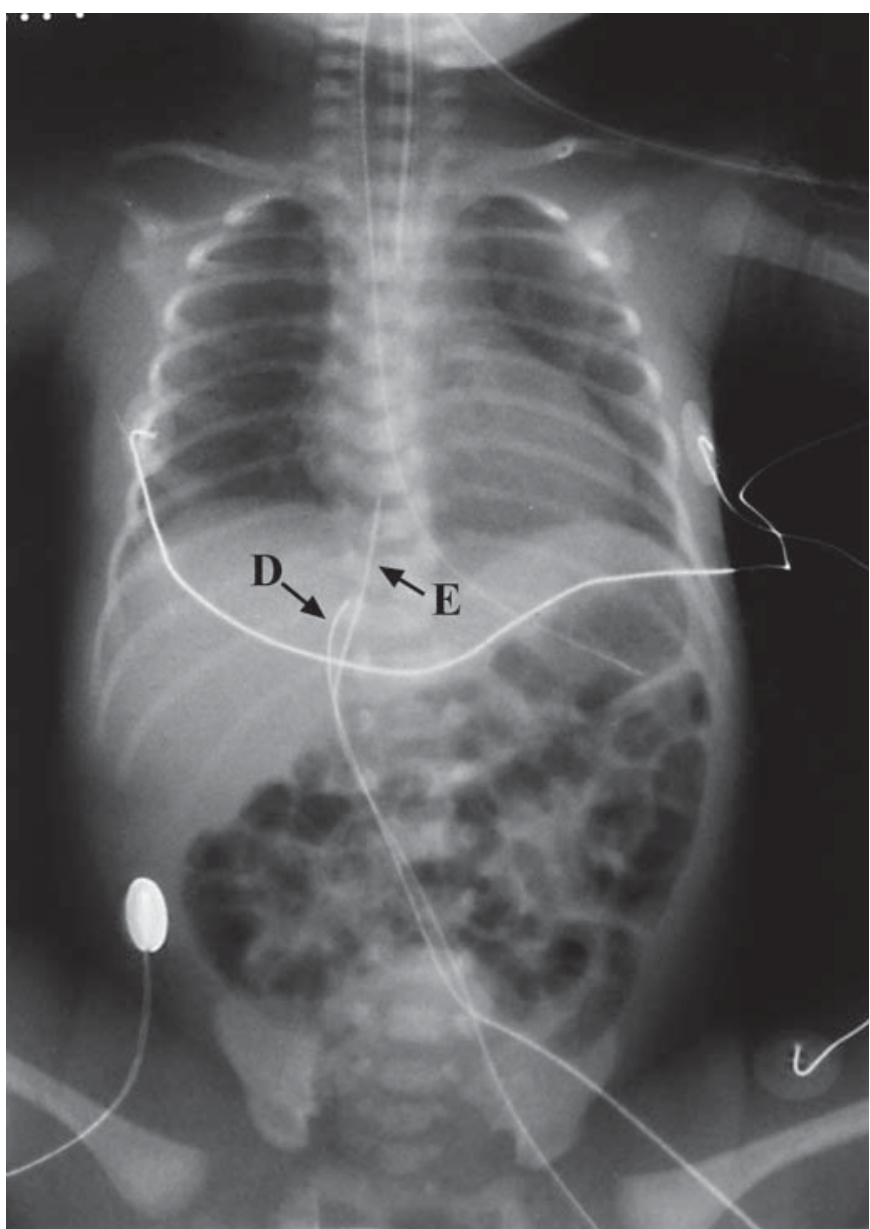

Fig. 2. Umbilical venous catheters. $D=$ First catheter; $E=$ second catheter.

still in the first and second days of life (table 1). Of the 6 failures, 5 of $15(33.3 \%)$ were male and 1 of $10(10 \%)$ female. Candida species was isolated from the tip of the second catheter in only 1 baby (patient 4 ) and no other catheter-related complication was recorded. There were no complications of necrotizing enterocolitis or pericardial effusion encountered.

\section{Discussion}

Umbilical venous catheterization is a common procedure in a neonatal unit. It is easy to perform but failures are also frequently seen. A major problem with the technique is the misdirection of the catheter into the portal system, where it could be hazardous. Success is achieved when the catheter is placed in the right atrium, and has been able to bring down the failure rate following the rec- ommendations of Shukla and Ferrara [10] for this procedure, from 12.6 to $4.6 \%$.

In this study we have shown the usefulness and safety of employing the 'double-catheter' technique when a misplaced catheter is encountered. Other investigators have reported similar successes. Davies et al. [8] attributed their success to the assumption that the first catheter had blocked the route towards the portal vein thereby allowing the second catheter an easier access to the right atrium. Schreiber et al. [11] described success with a similar technique in catheterizing the umbilical arteries when they were misdirected towards the internal iliac arteries. In the 2 cases of late catheterization, we assumed that the failure was likely due to the fact that the ductus venosus was closed by the time catheterisation was attempted. However, Loberant et al. [12] and Fugelseth [13] in two separate studies have shown that the ductus remains patent in almost all healthy full-term infants at $48 \mathrm{~h}$ of age and in around $75 \%$ of them at the age of 7 days. The chances for success seem better in preterm infants than in term as seen in some of our failure cases mostly in full-term babies. This could be partly explained by the fact that term babies have more muscular ductus venosus than preterm, thereby encouraging an early closure. Additionally, our term infants were sicker than the preterm. We have no explanation for the preponderance of the male infants who failed the procedure except that they were mostly full-term babies.

In our study, the actual length of the second catheter inserted was sometimes different from the calculated length based on the Shukla and Ferrara [10] recommendation because of the resistance caused by the first catheter or the need to get adequate free back flow from the second catheter.

In the Neonatal Intensive Care Unit of our hospital, blood sampling was one of the major indications for umbilical venous catheterization because the umbilical artery catheter could not be fixed or had to be removed because of complication. In addition, unfortunately, we do not have phlebotomists and nurses are understaffed. Blood sampling was especially frequent in those patients, and sampling via a properly placed umbilical venous catheter was believed to decrease exposure to prolonged manipulation and pain.

\section{Conclusion}

Insertion of a second umbilical venous catheter while the misplaced first catheter was in situ was performed safely in most neonates. 


\section{References}

$>1$ Seguin J, Fletcher MA, Landers S, Brown D, Macpherson T: Umbilical venous catheterizations: Audit by the study group for complications of perinatal care. Am J Perinatol 1994; 11:67-70.

-2 Loisel DB, Smith MM, MacDonald MG, Martin GR: Intravenous accesses in newborn infants: Impact of extended umbilical venous catheter use on requirement for peripheral venous lines. J Perinatol 1996;16:461-466.

3 Periera GR, Lim BK, Ing C, Medeiros HF: Umbilical vs. peripheral catheterization for parenetral nutrition in sick premature neonates. Yonsei Med J 1992;33:224-231.

4 Schwartz DS, Gettner PA, Konstantino MM, Bartley CL, Keller MS, Ehrenkranz RA, Jacobs HC: Umbilical venous catheterization and the risk of portal vein thrombosis. J Pediatr 1997; 131:760-762.
5 Landers S, Moise AA, Fraley JK, Smith EO, Baker CJ: Factors associated with umbilical catheter-related sepsis in neonates. Am J Dis Child 1991;145:675-680.

6 Savani RC, Valentini RP, Mimouni F: Neonatal radiology casebook: Pericardial effusion as a complication of umbilical catheterization. J Perinatol 1990;10:443-445.

7 Van Niekerk M, Kalis NN, Van der Merwe PL: Cardiac tamponade following umbilical vein catheterization in a neonate. S Afr Med J 1998; 88(suppl 2):C87-C90.

8 Davies MW, Cartwright DW: Insertion of umbilical venous catheters past the ductus venosus using the double catheter technique. Arch Dis Child Fetal Neonatal Ed 1998;78:F234.

$\checkmark 9$ Mandel D, Mimouni F, Littner Y, Dollberg S: Double catheter technique for misdirected umbilical vein catheter. J Pediatr 2001;139:591592.
10 Shukla H, Ferrara A: Rapid estimation of insertional length of umbilical catheters in newborns. Am J Dis Child 1986;140:786788.

11 Schreiber MD, Perez CA, Kitterman JA: A double-catheter technique for caudally misdirected umbilical arterial catheters. J Pediatr 1984;104:768-769.

12 Loberant N, Barak M, Gaitini D, Herskovits M, Ben-Elisha M, Roguin N: Closure of the ductus venosus in neonates: Findings on realtime gray-scale, color-flow Doppler, and duplex Doppler sonography. Am J Roentgenol 1992;159:1083-1085.

13 Fugelseth D, Lindemann R, Liestøl K, Kiserud $\mathrm{T}$, Langslet A: Ultrasonographic study of ductus venosus in healthy neonates. Arch Dis Child Fetal Neonatal Ed 1997;77:F131F134. 